\title{
Comparison of Muscle Activity of the Erector Spinae according to Thoracic Spine Extension Mobility
}

\author{
Sil-ah Choi, PT, Ph.D ${ }^{1}$; Sung-hoon Jung, PT, Ph.D ${ }^{2}$ \\ ${ }^{1}$ Department of Physical Therapy, College of Health Science, Ansan University, South Korea \\ ${ }^{2}$ Department of Physical Therapy, College of Health Science, Yonsei University, South Korea
}

Background During trunk extension, the thoracic extensor is decreased and the lumbar extensor is excessively activated, which is a factor inducing low back pain.

Purpose The purpose of this study is to compare the muscle activity of the erector spinae of the thoracis and the lumborum during trunk extension according to the thoracic spine extension mobility.

Study design Cross-sectional study.

Methods 94 participants measured thoracic spine extension mobility and assigned low mobility group ( $n=31)$ and high mobility group $(n=31)$ according to the mean and standard deviation. The muscle activity of the erector spinae was measured when participants maintained their trunk extension at the prone position. An independent $t$-test was used to compare the muscle activity between the low and high mobility groups.

Results The muscle activity of longissimus thoracis, the ratio of longissimus thoracis:iliocostalis lumborum pars lumborum, and iliocostalis lumborum pars thoracis:iliocostalis lumborum pars lumborum was significantly different between the high and low mobility group $(p<0.05)$.

Conclusions The muscle activity of longissimus thoracis and ratio between the thoracis and the lumborum of the erector spinae are reduced in the low mobility group than the high mobility group during trunk extension.

Key words Erector spinae; Muscle activity; Thoracic spine extension mobility; Trunk extension.

\author{
J Musculoskelet \\ Sci Technol \\ 2021; 5(2): 67-71 \\ Published Online \\ Dec 31, 2021 \\ pISSN 2635-8573 \\ eISSN 2635-858
}

\section{Article History}

Received 30 Sep 2021

Revised 23 Oct 2021

(1st)

Revised 29 Nov 2021

(2nd)

Accepted 30 Nov 2021

\section{CONTACT}

movt_architect@daum.net

Sung-hoon Jung,

Department of Physical

Therapy, College of

Health Science, Yonsei

University, South Korea

This is an Open-Access article distributed under the terms of the Creative Commons Attribution Non-Commercist ribution (ho: Conmercial License (hittp./creativecommons. org/licenses/by-nc/4.0) which permits unrestricted non-commercial use, distribution, and reproduction in any medium, provided the origina work is properly cited.

\section{INTRODUCTION}

Mechanical pain disorders of the thoracic spine are commonly associated with impairment of thoracic spine mobility. ${ }^{1-3}$ Impairment of thoracic spine mobility is frequently reported in axial rotation and extension. ${ }^{4}$ Thoracic spine extension mobility (TE) is required in the end range of shoulder flexion, ${ }^{5}$ and is essential for ideal pattern of trunk extension.

Prone trunk extension is performed to check the ideal trunk extension pattern. ${ }^{6}$ Park et al. reported that those with a slouched posture had smaller thoracic spine extension and greater lumbar extension during the prone trunk extension compared to those without slouched posture. ${ }^{7}$ Also, the muscle activity ratio between the thoracis and lumborum of erector spinae was lower in those with a slouched posture. ${ }^{7}$ During prone trunk extension, the thoracic extensor is decreased and the lumbar extensor is excessively activated, which is a factor inducing low back pain. ${ }^{8-10}$ Therefore, muscle activity of thoracic erector spinae was emphasized to manage and prevent low back pain. ${ }^{11}$

During the thoracic extension, the thoracic erector spinae such as longissimus thoracis (LT), and iliocostalis lumborum pars thoracis (ICT) are activated. ${ }^{6,7}$ However, since the erector spinae muscle of lumborum such as iliocostalis pars lumborum (ICL) can be used as compensation during trunk 
extension, it is important to confirm the ratio between the thoracis and the lumborum of the erector spinae such as LT:ICL and ICT:ICL. ${ }^{67,12}$ Therefore, the current study compares the muscle activity ratio between the thoracis and the lumborum of the erector spinae according to TE during prone trunk extension. It was hypothesized that the individuals with high TE will have greater muscle activity of thoracis and ratio between the thoracis and the lumborum of the erector spinae compared with low TE.

\section{METHOD}

\section{Participants}

Ninety-four healthy individuals who thought they had hyperkyphosis were recruited through Internet advertisements in Table 1. Individuals with the following characteristics were excluded: scoliosis and a history of spinal column fracture, spinal tumors and related malignancies, congenital spinal anomalies, cancer, or rheumatoid arthritis. ${ }^{13}$ Participants measured thoracic spine extension mobility (TE) using a spinal mouse (Idiag AG, Fehraltorf, Switzerland) and assigned groups according to mean and standard deviation (mean=24.76, standard deviation=9.69). Participants with TE greater than $1 / 2$ standard deviation from the mean were assigned to the high mobility group (>29.6, n=31), and those with TE less than $1 / 2$ standard deviation from the mean were assigned to the low mobility group $(<19.9, \mathrm{n}=31)$. Thirty-two participants who did not meet the group assignment criteria were excluded from the study. The study was approved by the Institutional Review Board of Yonsei University Wonju (1041849-202101-BM009-01).

\section{Thoracic spine extension mobility}

The angle of TE was defined as the difference between the angle of thoracic kyphosis in standing and the end range angle during thoracic extension. ${ }^{1}$ The angle of thoracic kyphosis in standing and the end range angle during thoracic extension was measured using a Spinal Mouse (Idiag AG, Fehraltorf, Switzerland). To measure the angle of thoracic kyphosis, each participant was instructed to stand in a comfortable (habitual) position facing the front with the crossed-arm (Figure 1). ${ }^{14}$ Then, the participant wrapped both hands behind the head with the upper arms against the ears for the end range angle during thoracic extension. ${ }^{14}$ The participants were instructed to "point the

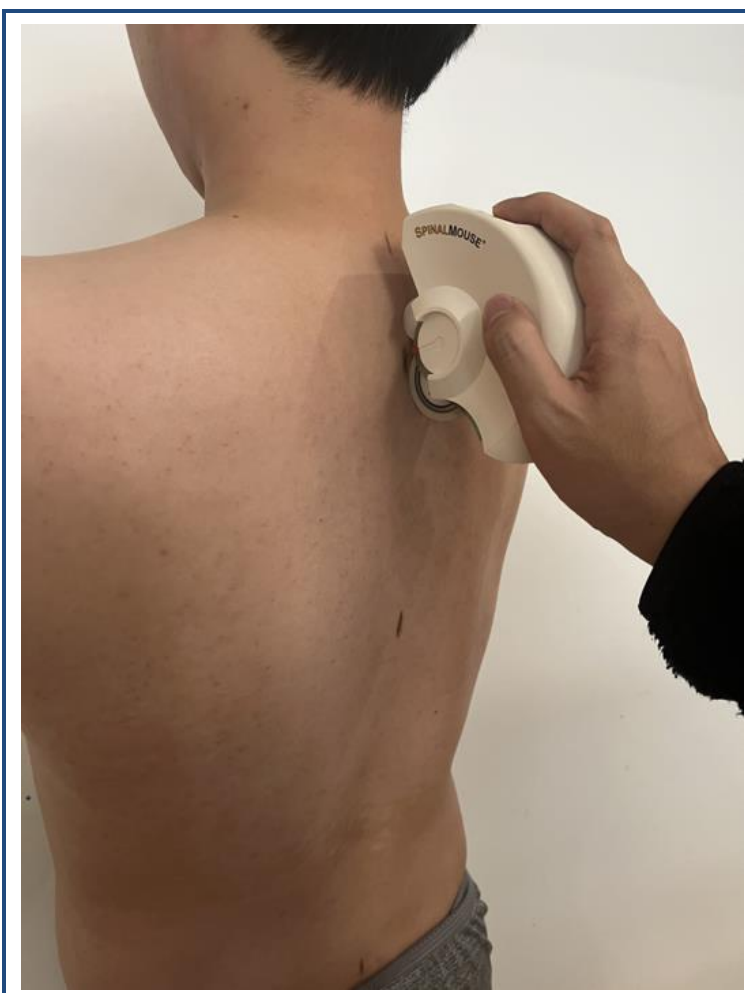

Figure 1. Measurement of thoracic kyphosis.

Table 1. Demographic data

\begin{tabular}{ccccc}
\hline & Low mobility group & High mobility group & $t$ & $p$ \\
\hline Age $(\mathrm{yrs})$ & $36.65 \pm 6.40$ & $33.81 \pm 7.05$ & 1.660 & 0.102 \\
\hline Sex (male/female) & $25 / 6$ & $18 / 13$ & - & - \\
\hline Height $(\mathrm{cm})$ & $171.56 \pm 7.91$ & $169.06 \pm 6.89$ & 1.327 & 0.189 \\
Weight $(\mathrm{kg})$ & $74.68 \pm 15.26$ & $73.49 \pm 15.59$ & 0.302 & 0.763 \\
\hline Body mass index $\left(\mathrm{kg} / \mathrm{m}^{2}\right)$ & $25.15 \pm 3.83$ & $25.55 \pm 4.21$ & -0.398 & 0.692 \\
\hline Thoracic $\mathrm{kyphosis}\left(^{\circ}\right)$ & $41.03 \pm 8.45$ & $43.73 \pm 9.42$ & -1.189 & 0.239 \\
\hline $\operatorname{TE}\left({ }^{\circ}\right)$ & $13.87 \pm 4.81$ & $35.46 \pm 4.59$ & -18.082 & $0.000^{*}$ \\
\hline
\end{tabular}

TE: thoracic spine extension mobility, Data are expressed as mean \pm standard deviation, ${ }^{*} p<0.05$. 
elbows toward the ceiling and arch backward." We measured the angle of thoracic kyphosis and end range during thoracic extension twice. For global spinal angles, the device is a reliable and valid device. ${ }^{15-17}$

\section{Instrumentation}

\section{1) Spinal mouse}

The angle of thoracic kyphosis and end range during thoracic extension was measured using a Spinal Mouse system (Idiag, Fehraltdorf, Switzerland). ${ }^{18}$ The Spinal Mouse has accelerometers that record change of inclination and intersegmental distance of spinous processes. The device contains two rolling wheels follow the spinous processes of the spine, and the data are transferred from the device to a computer (sampling frequency of approximately $150 \mathrm{~Hz}$ ). ${ }^{19}$ These data are used to calculate the relative angles between the vertebrae and total angle of sagittal plane using Spinal Mouse software. For global spinal angles, the device is a reliable and valid device. ${ }^{15-17}$

\section{2) Electromyography}

The muscle activity of the LT, ICL, and ICT was measured using the Noraxon Ultium ESP System (Noraxon USA, Inc., Scottsdale, AZ) according to Criswell. ${ }^{20}$ Skin impedance was reduced by shaving excess body hair, if necessary, gently abrading the skin with fine grade sandpaper, and wiping the skin with alcohol swabs. Signals were collected using MyoMuscle ${ }^{\text {TM }}$ MR3 3.14.52 (Noraxon Inc.). The raw electromyography signals were band-pass filtered $(20-450 \mathrm{~Hz})$, and the root mean square values were calculated using a 50-ms window. Data were recorded at a sampling rate of $2,048 \mathrm{~Hz}$. The muscle activity was measured when participants maintained their thoracic extension at the prone position (Figure 2). ${ }^{14}$ And the muscle activity was expressed in \% maximum voluntary isometric contraction.

\section{Statistical analysis}

Statistical analyses were conducted with SPSS ver. 20.0 (SPSS Inc., Chicago, IL, USA). The Kolmogorov-Smirnov test was used to confirm that the data were normally distributed. An independent $t$-test was used to compare the muscle activity of LT, ICT, ICL, ratio of LT:ICL, and ICT:ICL between the low and high mobility groups. A value of $p<0.05$ was taken to indicate statistical significance.

\section{RESULT}

All variables showed a normal distribution in Kolmogorov-
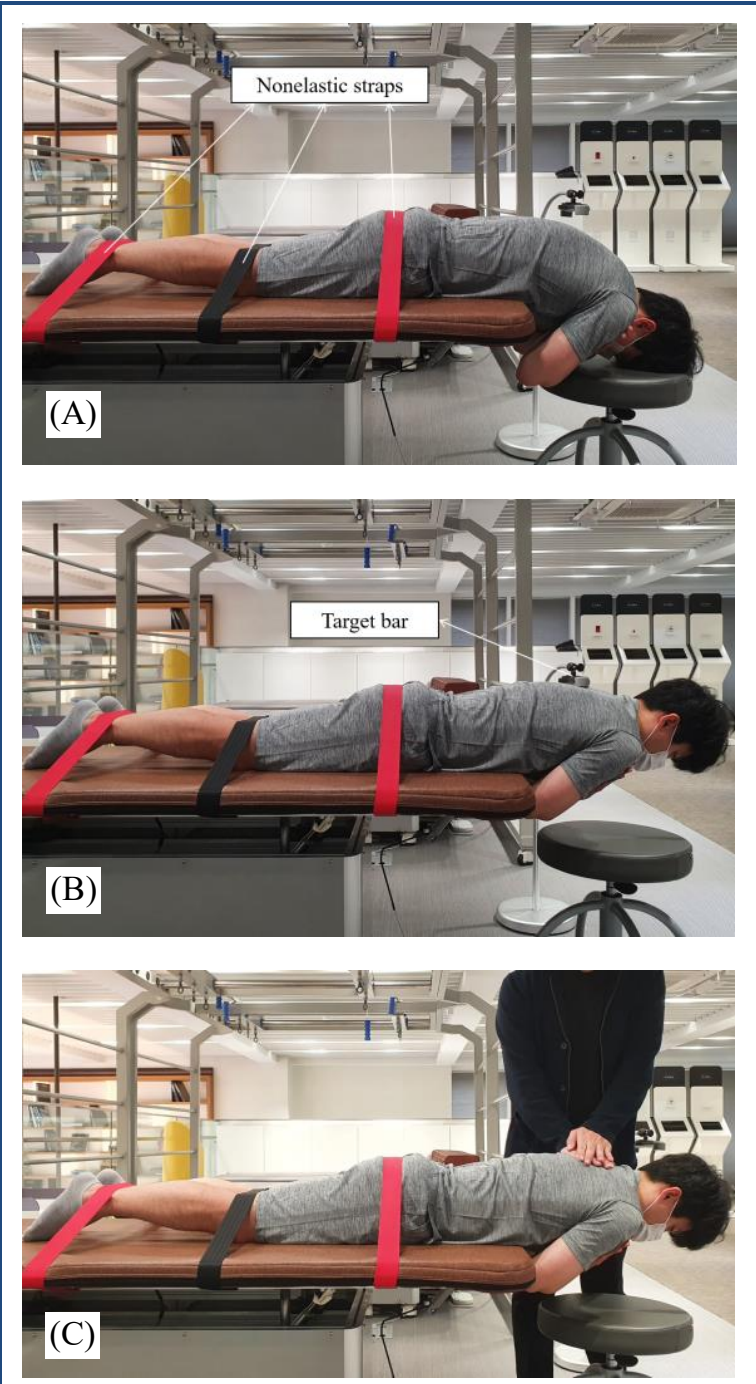

Figure 2. Prone trunk extension. (A) Start position. The participant's xiphoid process was aligned at the table edge, participants crossed their arms across their chest, and the lower extremities were fixed with nonelastic straps (hip, knee, and ankle). (B) Prone thoracic extension. The participants raised their bodies to the target bar and hold this position for $5 \mathrm{~s}$. This target bar was set to the height of the T6 level. (C) Maximum voluntary isometric contraction. While the participant is performing the prone trunk extension, the examiner pressed the upper thorax downward to measure the maximum voluntary isometric contraction.

Smirnov test $(p>0.05)$. The result for the independent t-test between the low and high mobility groups is shown in Table 2. The muscle activity of LT, the ratio of LT:ICL, and ICT:ICL significantly increased in the high mobility group $(p<0.05)$. 
Table 2. Comparison of the muscle activity between the low and high mobility groups

\begin{tabular}{ccccc}
\hline & Low mobility group & High mobility group & $t$ & $p$ \\
\hline LT & $23.68 \pm 8.74$ & $35.20 \pm 19.08$ & -3.057 & $0.003^{*}$ \\
ICT & $34.63 \pm 12.21$ & $38.54 \pm 18.03$ & -1.000 & 0.322 \\
ICL & $49.40 \pm 13.72$ & $48.23 \pm 17.81$ & 0.290 & 0.773 \\
Ratio of LT:ICL & $0.51 \pm 0.18$ & $0.73 \pm 0.24$ & -4.073 & $0.000^{*}$ \\
Ratio of ICT:ICL & $0.71 \pm 0.16$ & $0.80 \pm 0.17$ & -2.236 & $0.029^{*}$ \\
\hline
\end{tabular}

LT, longissimus thoracis; ICT, iliocostalis lumborum pars thoracis; ICL, iliocostalis lumborum pars lumborum.

Data are expressed as mean \pm standard deviation, ${ }^{*} p<0.05$.

\section{DISCUSSION}

In a previous study, the difference in muscle activity during prone trunk extension was compared by dividing groups according to alignment such as slouched posture. ${ }^{7}$ However, since the muscle activity is accompanied by mobility, not only alignment but also movement should be considered. Therefore, in this study, the high mobility group and the low mobility group were divided and compared according to TE, and there was a significant difference between the groups in ratio of LT:ICL, ICT:ICL, and muscle activity of LT.

The ratio of LT:ICL and ICT:ICL means the balance of the erector spinae muscle, and the closer the value is to 1 , the better the balance of erector spinae between thoracis and lumborum. Park et al. reported that the ratios of individuals without slouched posture were 0.82 and 0.88 (LT:ICL, ICT:ICL sequentially), which is similar to the ratio of the high mobility group in this study $(0.73$ and 0.80$) .{ }^{7}$ Therefore, as a result of this study, it can be confirmed that the balance of the erector spinae between thoracis and lumborum is reduced in the low mobility group, which can be a factor of low back pain. ${ }^{8-10}$

Jung et al. reported that muscle activity of LT decreased after improving thoracic extension by applying thoracic mobilization to individuals with hyperkyphosis. ${ }^{14}$ However, in this study, muscle activity of LT was significantly larger in the high mobility group than the low mobility group. This suggests that not only musculoskeletal factors but motor control factors should be considered in order to improve kinetics including muscle activity as well as kinematics.

Our study has some limitations. First, we enrolled relatively young participants. Thus, our findings cannot be generalized, to participants with old-age. Second, we did not investigate lumbar kinematics during the experiment; future studies should observe lumbar kinematics to confirm the compensatory movement of the lumbar spine during prone trunk extension.

\section{CONCLUSIONS}

We found that the muscle activity of LT, and the ratio between the thoracis and the lumborum of the erector spinae is reduced in the low mobility group than the high mobility group during the prone trunk extension. Therefore, we suggest that it should be considered to activate the erector spinae of thoracis and to maintain the balance between the thoracis and lumborum of the erector spinae when treating and managing patients with low thoracic extension mobility.

\section{Key Points}

Question Is there any difference in muscle activity of the erector spinae in individuals with low thoracic spine extension mobility compared to individuals with high thoracic spine extension mobility?

Findings The muscle activity of the erector spinae of thoracis, and the ratio between the thoracis and the lumborum of the erector spinae is reduced in individuals with low thoracic extension mobility than individuals with high thoracic extension mobility.

Meaning When treating and managing patients with low thoracic extension mobility, it should be considered to activate the erector spinae of thoracis and to maintain the balance between the thoracis and lumborum of the erector spinae.

\section{Article information}

Conflict of Interest Disclosures: None.

Funding/Support: None.

Acknowledgment: None.

Ethic Approval: The study was approved by the Institutional Review Board of Yonsei University Wonju (1041849-202101-BM-009-01). 


\section{REFERENCES}

1. Edmondston S, Waller R, Vallin P, Holthe A, Noebauer A, King E. Thoracic spine extension mobility in young adults: influence of subject position and spinal curvature. J Orthop Sports Phys Ther. 2011;41(4):266-273.

2. Park JW, Choung SD. Effects of the muscle energy technique and the self-stretching exercise of the pectoralis minor on the pulmonary function of young adults with thoracic kyphosis. J Musculoskelet Sci Technol. 2020;4(1):6-12.

3. Jung SH, Ha SM, Kim JH, Gwak GT, Kim SJ. Reliability of axial-thoracolumbar spine rotation range measurements. J Musculoskelet Sci Technol. 2018;2(1):20-23.

4. Edmondston S, Singer K. Thoracic spine: anatomical and biomechanical considerations for manual therapy. Man Ther. 1997;2(3):132-143.

5. Kebaetse M, McClure P, Pratt NA. Thoracic position effect on shoulder range of motion, strength, and threedimensional scapular kinematics. Arch Phys Med Rehabil. 1999;80(8):945-950.

6. Sahrmann S. Movement system impairment syndromes of the extremities, cervical and thoracic spines-e-book. Elsevier Health Sciences; 2010.

7. Park KH, Oh JS, An DH, et al. Difference in selective muscle activity of thoracic erector spinae during prone trunk extension exercise in subjects with slouched thoracic posture. PMR. 2015;7(5):479-484.

8. Panjabi MM. The stabilizing system of the spine. Part I. Function, dysfunction, adaptation, and enhancement. $J$ Spinal Disord. 1992;5:383-383.

9. Renkawitz T, Boluki D, Grifka J. The association of low back pain, neuromuscular imbalance, and trunk extension strength in athletes. Spine J. 2006;6(6):673-683.

10. Renkawitz T, Linhardt O, Grifka J. Electric efficiency of the erector spinae in high performance amateur tennis players. J Sports Med Phys Fitness. 2008;48(3):409.

11. Ha SM, Jung SH, Kim JH, Gwak GT. Selective activation of thoracic extensor muscles during 3 different trunk extensor strengthening exercise. $J$ Musculoskelet
Sci Technol. 2017;1(1):31-35.

12. Sahrmann S. Diagnosis and treatment of movement impairment syndromes. Elsevier Health Sciences; 2001.

13. Kamali F, Shirazi SA, Ebrahimi S, Mirshamsi M, Ghanbari A. Comparison of manual therapy and exercise therapy for postural hyperkyphosis: a randomized clinical trial. Physiother Theory Pract. 2016;32(2):9297.

14. Jung SH, Hwang UJ, Ahn SH, Kim JH, Kwon OY. Effects of manual therapy and mechanical massage on spinal alignment, extension range of motion, back extensor electromyographic activity, and thoracic extension strength in individuals with thoracic hyperkyphosis: a randomized controlled trial. Evid Based Complement Alternat Med. 2020;2020:6526935.

15. Guermazi M, Ghroubi S, Kassis M, et al. Validity and reliability of spinal mouse to assess lumbar flexion. Ann Readapt Med Phys. 2006;49(4):172-177.

16. Mannion AF, Knecht K, Balaban G, Dvorak J, Grob D. A new skin-surface device for measuring the curvature and global and segmental ranges of motion of the spine: reliability of measurements and comparison with data reviewed from the literature. Eur Spine J. 2004;13(2): 122-136.

17. Post R, Leferink V. Spinal mobility: sagittal range of motion measured with the spinalmouse, a new noninvasive device. Arch Orthop Trauma Surg. 2004; 124(3):187-192.

18. Jung SH, Hwang UJ, Kim JH, Ha SM, Kwon OY. Correlation among non-radiological measurements for thoracic kyphosis. J Musculoskelet Sci Technol. 2020; $4(1): 1-5$.

19. Livanelioglu A, Kaya F, Nabiyev V, Demirkiran G, Firat T. The validity and reliability of "Spinal Mouse" assessment of spinal curvatures in the frontal plane in pediatric adolescent idiopathic thoraco-lumbar curves. Eur Spine J. 2016;25(2):476-482.

20. Criswell E. Cram's introduction to surface electromyography. Jones \& Bartlett Publishers; 2010. 